\title{
ADVOCACIÓN MARIANA Y CEREMONIAL RELIGIOSO EN LA DOCUMENTACIÓN DEL ARCHIVO DE LA CATEDRAL DE MÁLAGA: UNA APROXIMACIÓN A LAS FIESTAS, MISAS Y DOTACIONES
}

\author{
Elizabeth García GiL ${ }^{*}$ \\ Universidad de Málaga
}

\begin{abstract}
RESUMEN
El presente trabajo tiene como objetivo realizar una aproximación a la presencia mariana en el ceremonial religioso acontecido en la Catedral de Málaga durante los siglos XVI-XIX. La metodología seguida para llevar a cabo la investigación ha sido el análisis de las fuentes documentales del Archivo Catedralicio de la capital malagueña, lo que ha permitido obtener una sustanciosa información de carácter social, religioso, económico e incluso identitario. Los escenarios sociales donde la representación de María imperaba eran las misas y las fiestas. Las dotaciones ofrendadas por los feligreses quedaron recogidas en los libros de censos, aniversarios y memorias que, junto con las mandas testamentarias, se convirtieron en el contexto ideal para manifestar su devoción y culto.
\end{abstract}

PALABRAS CLAVE: Virgen María, ceremonial religioso, Archivo de la Catedral de Málaga, advocación mariana, liturgia, mandas testamentarias

*elizabeth_gargi@uma.es 


\title{
MARIAN ADVOCATION AND RELIGIOUS CEREMONIAL IN THE DOCUMENTATION OF THE ARCHIVE OF THE CATHEDRAL OF MALAGA: AN APPROACH TO FESTIVITIES, MASSES AND ENDOWMENTS
}

\author{
Elizabeth García GiL ${ }^{*}$ \\ Universidad de Málaga
}

\begin{abstract}
The present paper aims to make an approach to the Marian presence in the religious ceremony in the Cathedral of Malaga during the $16^{\text {th }}-19^{\text {th }}$. The methodology to be followed to carry out our research has been the analysis of documentary sources of the Cathedral Archive of Malaga city, what has allowed a substancial social, religious and economic character and even identity information. Social outcomes where the Marian presence prevailed were the masses and festivities. Endowment offered by parishioners were collected in books of censuses, anniversaries and memories, and developed in the context of ideal to express their devotion.
\end{abstract}

KEY WORDS: Virgin Mary, religious ceremonial, Archive of the Cathedral of Malaga, Marian advocation, liturgy, testamentary dispositions.

*elizabeth_gargi@uma.es 


\section{INTRODUCCIÓN}

El presente trabajo pretende realizar una aproximación al ceremonial religioso vinculado a los aspectos marianos que florecieron en la Málaga de los siglos XVI-XIX. Para ello, se ha realizado un análisis de la documentación generada por las instituciones eclesiásticas de la ciudad malagueña, focalizando especialmente la atención en el Archivo de la Catedral de Málaga ${ }^{1}$.

Si bien existen estudios individualizados sobre la figura de María, basados en fuentes documentales, la bibliografía que aborda directamente las misas en su honor es muy escasa. Solo se ha tocado la cuestión de forma colateral o en puntos muy localizados. Por ello, la intención de este trabajo es la de realizar una aproximación a la presencia mariana en los documentos conservados en el archivo catedralicio malagueño, en primer lugar, y el Archivo Histórico Diocesano de Málaga, en segundo lugar. Así pues, los libros de los diferentes organismos eclesiásticos han mostrado cómo esta presencia se manifiesta profusamente en procesiones, misas y fiestas de la Catedral de Málaga, la parroquia del Sagrario, el Hospital de Santo Tomás o el Hospital de la Caridad. Los criterios seguidos para el estudio de las fuentes documentales han sido guiados por su representatividad, accesibilidad y semejanza.

A través de la consulta documental se ha podido constatar que la música se ejecutaba como componente cardinal en las misas, las procesiones y las fiestas vinculadas a sus distintas advocaciones. Como afirma la especialista, la Dra. M. ${ }^{a}$ José de la Torre Molina², es importante dar la relevancia adecuada a la función y el propósito que la música tiene en los ceremoniales. En estas ceremonias, la música era empleada de forma consciente para embellecer la liturgia, cambiando según el tipo de celebración y generando espacios y modelos concretos que aportasen solemnidad

1. El presente artículo es el resultado de una Beca de Iniciación a la Investigación concedida por el Plan Propio de la Universidad de Málaga y desarrollada en el Departamento de Ciencias Históricas de la citada Universidad y en el Archivo Catedralicio de Málaga. Muestro mi agradecimiento a la Universidad de Málaga por su financiación y, asimismo, doy las gracias al personal del ACM, muy especialmente a su técnica de Archivo, la Dra. Susana E. Rodríguez de Tembleque García, por su buena disposición y ayuda durante los meses de disfrute de la beca. Igualmente, muestro mi gratitud al Catedrático de Historia Moderna, el Dr. Juan Jesús Bravo Caro, sin quien no hubiese podido ver la luz esta publicación.

2. M. J. Torre Molina (2010), 331. 
y representación institucional e identitaria ${ }^{3}$. Tampoco se pueden olvidar los trabajos del pionero en las investigaciones musicales que confieren a la Catedral de Málaga, el doctor Adalberto Martínez Solaesa, de quien destacan los trabajos sobre la historia musical y cultural que envuelve a la catedral malacitana ${ }^{4}$.

\section{CEREMONIAL RELIGIOSO Y ESTADO SOCIAL}

Las formas y modos de realizar el ceremonial a lo largo de la Historia han puesto de relieve los modelos religiosos. Es por ello por lo que las prácticas religiosas constituyen un campo muy amplio para analizar los diferentes tipos de sociedades. Conocer la forma en la que se realizaban ayuda a poner de manifiesto y comprender los modelos culturales de cada una de ellas. Al analizar las ceremonias se pueden revelar las distintas jerarquías sociales y su uso como instrumento de poder. Esto lo hemos podido constatar a través de las peticiones de misas en los testamentos postmorten.

Las misas o ciclos de misas recogidas en las memorias solían estar encargadas por personalidades de la época, pues solo las clases pudientes podrían permitirse abordar el pago de las misas perpetuas. Este tipo de ceremonial fúnebre hace notar aún más las diferencias de clases entre el ser humano, agudizando las divergencias sociales y económicas ante la muerte $^{5}$. Un ejemplo significativo se observa en el caso de Ana de Gamboa, quien encargó entre 42 y 70 misas anuales. En la documentación consultada aparece por primera vez en el año 1695. En el libro de memorias deja constancia de que "hasta 1775 tiene visitada y cumplida las

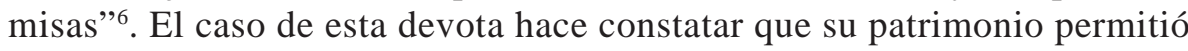
costear un número tan elevado de misas, a la vez de poner de manifiesto la religiosidad de su persona e intención de permanecer en el Purgatorio el menor tiempo posible, expiando sus pecados con las misas encargadas.

3. No se pretende hacer aquí un estudio musicológico, pero sí referir la importancia y la unión que la música tiene con el ceremonial religioso. Para abordar las cuestiones musicológicas sobre la realidad catedralicia malagueña, véanse los trabajos del doctor Martínez Solaesa o la doctora Torre Molina, de la Universidad de Málaga.

4. A. Martínez Solaesa (1996); A. Martínez Solaesa y L. Naranjo lorenzo (2004).

5. M. Reder Gadow (1986), 115.

6. Archivo Histórico Diocesano de Málaga (AHDM), caja 537, libro 2, fol. 7. Libro de Memorias encargados al Sagrario desde 1695 a 1776, Málaga. 
El carácter complejo de la religión y el ceremonial religioso precisa investigarlo desde diversas perspectivas, en diferentes ámbitos y periodos. Las razones de la significación religiosa dependerán del grupo social de pertenencia del individuo, siendo los lugares y las formas escogidas para profesar su fe un proceso de identificación social. Es ahí donde entran en juego las intenciones políticas, económicas, culturales y religiosas. La Iglesia será la esfera perfecta para la demostración de las identidades colectivas, convirtiendo las misas en un medio de poder que reportará prestigio y autoridad pasada la vida terrenal del difunto.

De esta manera, la Iglesia supo mitigar el miedo a la muerte tan presente en las mentalidades de una sociedad que recordaba muy de cerca el cambio en la forma de divisarla, una vez transcurrido el periodo de mayor mortandad en la baja Edad Media: nos referimos a las secuelas dejadas por la Peste Negra en el imaginario de las comunidades humanas de ese periodo histórico. Para ello, utilizaron los recursos documentales que disponían para asegurar el camino al más allá7.

Las misas en honor a difuntos constituyen un medio para analizar aspectos materiales, sociales y simbólicos. La selección de los distintos tipos de misas encontradas en los fondos archivísticos consultados, se vincula con manifestaciones de compromisos, deuda o cariño. Con ello, la antropología ha demostrado que el estudio de la religiosidad arroja luz para comprender el entramado cultural, la naturaleza y la estructura de un orden social dado ${ }^{8}$. Con estos preceptos se esperaría poner en evidencia el valor del comportamiento tras la muerte como signo de identidad religiosa. Las misas devocionales a favor de los difuntos distinguirían una dicotomía entre las personas poderosas y las excluidas, aquellas sin medios económicos para permitirse su pago. Por tanto, no sería extraño concluir con la idea de que las misas de difuntos, como podrían ser las perpetuas, serían un hecho privilegiado donde se mostrarían las particularidades religiosas y sociales.

\section{EL CULTO MARIANO EN MISAS Y FIESTAS}

Aunque la advocación mariana puede datarse desde la Antigüedad, el siglo XIII sobresale por comenzar a desarrollar nuevas formas de cultos a este personaje sagrado. El ceremonial litúrgico empezaría a tener

7. P. Ostos Salcedo (2011), 275.

8. S. Rodríguez Becerra (2000), 154-155. 
como protagonista a María, y su culto continuaría desarrollándose con la difusión que las nuevas órdenes religiosas le darían. Llegada la Edad Moderna su devoción no decrecería, todo lo contrario. Los estudios sobre el tema constatan nuevas formas de veneración. A partir del siglo XV se inicia una etapa secular más fecunda de la eortología mariana, en la que adquiere mayor relevancia la fiesta de la Inmaculada Concepción, tras la definición del dogma por Pío IX el 8 de diciembre de $1854^{9}$. Esta fiesta pone fin a las peticiones de la corriente contrarreformista reivindicada durante siglos en los distintos países, y sobre todo España, surgiendo así el fervor mariano ${ }^{10}$.

\subsection{Misas}

Las misas de los difuntos constituyen un campo muy sugestivo para analizar las mentalidades de los feligreses. El tránsito de la vida terrenal a la celestial era una cuestión de vital importancia para un creyente. Desde el siglo XIII el Purgatorio triunfó socialmente y comenzó a impregnar en las mentalidades de los feligreses. Con la llegada de este infierno temporal, una de las consecuencias que traería el Purgatorio sería la vinculación entre vivos y muertos, que resultaría efectiva en el caso de los sufragios ${ }^{11}$.

La escatología católica respalda que en ese momento se produce el abandono del alma para realizar un juicio individual donde el devoto conoce su destino. En la mayoría de los casos pasaría al Purgatorio, un estado que permitiría la liberación de sus pecados y ascensión hacia estancias celestiales. Por este motivo la Iglesia ofrecía medios como las misas pro animas o misas pro remedio animae, fórmulas habituales insertas en las actas de dotación para liberar las penas del alma del difunto y facilitar su rápida elevación celestial. El modo más usual para disponer estas misas, era dejarlas reflejadas en escrituras públicas, preferentemente testamentos. De esta manera era más sencillo que se expresase la voluntad del fallecido de dejar parte de su patrimonio en las distintas obras piadosas tendentes a alcanzar la salvación de su alma ${ }^{12}$. La religiosidad popular mariana reconoce a María el papel de Madre y Señora intercesora, mostrándola como mediadora en los testamentos y últimas voluntades. La inclusión de las

9. M. Righetti (1955), 893-894.

10. F. Fernández Basurte (1994), 195.

11. J. Le Goff (1985), 334-335.

12. M. J. Collado Ruiz (2012), 305. 
devociones marianas en la documentación refleja lo extendido de estas prácticas devocionales ${ }^{13}$.

Entre los diferentes volúmenes consultados destaca el libro de aniversarios datado "hacia el año 1580", donde aparecen la "Relación de memorias e aniversarios y procesiones que esta Santa Iglesia haze este año e de qué manera son obligaciones a las hazer e la doctación y cantidad de maravedíes que dexan o dexasen para las dichas doctaciones”14. En el mismo figura la relación de memorias, aniversarios y procesiones de la catedral de Málaga, suponiendo un total del $33 \%$ de misas de difuntos ofrendadas a las diferentes advocaciones marianas veneradas en la capital malagueña. Estas misas de réquiem cumplen los cánones mencionados anteriormente. Entre ellos se podría mostrar el de Francisco de Melgar, de quien se recoge lo siguiente en los memoriales:

Don Francisco de Melgar, maestrescuela, Vigilia de Cicilia se haze commemoraciçion a la capilla del dicho maestrescuela. Y otro día siguiente se dize una missa de la dicha Santa por el anima del dicho maestrescuela y se haze procesçion este dicho dia repartense en todo esto dos mil ducados. Docto el mismo don Francisco de Melgar que a los XV de diciembre en la tarde se vaya en procesçion a la capilla de Santa Cicilia y se haga una commemoraçion de la fiesta de nuestra señora de la Concepcion y otro dia siguiente se dize missa de nuestra señora por su anyma repartense otros ducados.

Ytem, docto el mismo don Francisco de Melgar que a los que se dize se le diga una vigilia de difuntos y otro dia de missa de requien cantada por su anima repartense otros MDII reales y XVI maravedies ${ }^{15}$.

En este ejemplo podemos observar la pompa funeraria y el poder económico previsto para ello. Además, la música sigue presente en estos actos solemnes, siendo una advocación femenina la elegida para honrar con esta misa de difuntos. Al realizar el estudio de las fuentes documentales corroboraremos nítidamente que un porcentaje muy elevado de las funciones musicales concertadas en la capilla de música de la catedral malagueña eran misas ${ }^{16}$, ya fuesen para celebrar fiestas de santidades de

13. S. Gómez Navarro (2008), 68-69.

14. Archivo de la Catedral de Málaga (ACM), leg. 161, n. ${ }^{\circ}$ 2. Libro de Memorias, Aniversarios y Procesiones de la Catedral de Málaga hacia el año 1580.

15. ACM, leg. 161, n. ${ }^{\circ}$ 2, s. f. Relación de Memorias, Aniversarios y Procesiones de la Catedral de Málaga hacia 1580 y censos cobrados durante el año 1623.

16. M. J. Torre Molina (2010), 336. 
las diferentes instituciones, en las misas de los patronos, de profesión de las monjas o en misas de difuntos, como la que se acaban de ejemplificar, memorias, aniversarios o dotaciones.

Otro libro de memorias significativo es el referido a las misas perpetuas encargadas a la parroquia del Sagrario de la Iglesia Catedral de Málaga, también conocida como parroquia de Santa María la Mayor ${ }^{17}$; al Hospital de la Caridad; al Hospital Santo Tomás; y a la propia Catedral. Son reseñables las encargadas entre 1695-1776, pues el $44 \%$ de las misas rezadas y cantadas están dedicadas a las distintas advocaciones de la Virgen María, destacando especialmente las de la Concepción, la Anunciación, la Asunción y la Encarnación ${ }^{18}$.

Dentro de la hagiografía femenina se encuentran diversos paradigmas que se manifiestan a través de misas. Un ejemplo de ello lo encontramos en el Decreto Real del 19 de julio de 1647, al conceder el oficio a los santos mártires, entre los que destaca el de santa Paula, patrona de Málaga. En él conminan a celebrar una misa y se diga un rezo sub ritu suplici el 17 de junio ${ }^{19}$.

De idéntica forma, la música tendrá en este ceremonial religioso un lugar preeminente. Las fuentes documentales recogen el grado de solemnidad con el que se celebraban estos actos litúrgicos dedicados a los santos mártires, entre los que se encontraba santa Paula. El decreto de Su Santidad sobre el oficio a esta patrona malagueña también se extendió a los reinos de Castilla y León, viendo así la importancia que designaba tal actividad. Años más tarde las fiestas en honor a san Ciriaco y santa Paula quedan coleccionadas en el "Quaderno de obligaciones que deben cumplir los Músicos de voz, Monistriles y demás Instumentristas de la Capilla de Música de la Santa Iglesia Catedral de Málaga”, donde se reglamenta el itinerario a seguir a la hora de celebrar estas fiestas, incluidas las de la Concepción ${ }^{20}$.

El cuaderno está dividido en cuatro partes. En la primera aparecen las disposiciones generales; la segunda apunta el orden e importancia de las ceremonias festivas; una tercera recoge la cronología y particularidades de cada fiesta; y una última donde se inscribe una disposición final para

17. V. González SÁnchez (1994), 455.

18. AHDM, leg. 537, n. ${ }^{\circ}$ 2. Libro de Memorias, 1695-1776.

19. ACM, leg. 35, s. f. Decreto de la Curia Romana por el que se extiende el rezo a los santos mártires Paula y Ciriaco, patronos de Málaga. 19 de julio de 1647.

20. A. T. Pino Romero (2010), 177. 


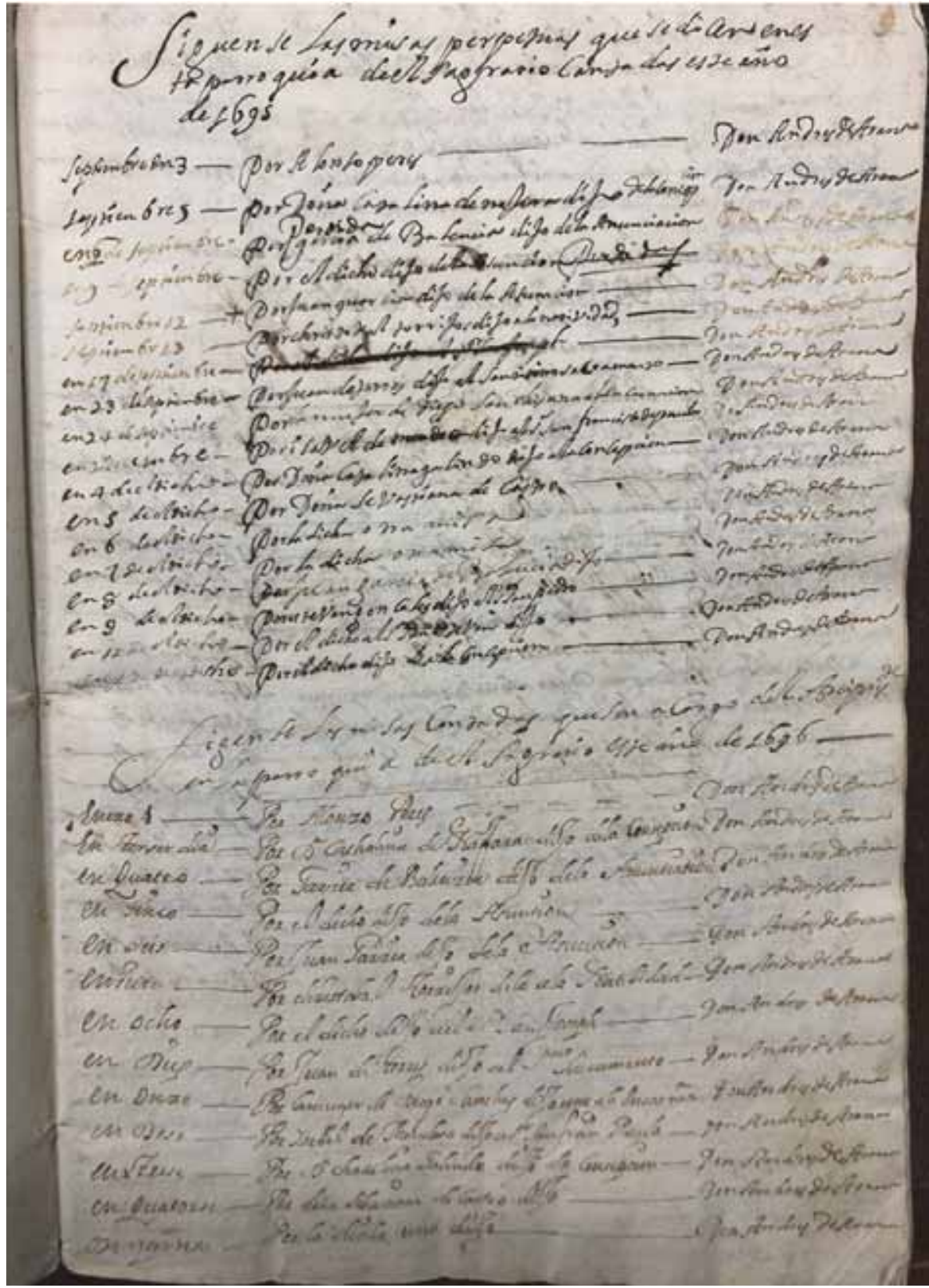

Imagen 1. Página del libro de memorias de misas por difuntos donde se muestran las misas perpetuas que se siguen en la parroquia del Sagrario entre los años 1695-1776, ofrendadas a las distintas advocaciones marianas. AHDM, leg. 537, n. ${ }^{\circ} 2$. 
la entrada y salida de músicos del coro de la catedral ${ }^{21}$. Estas ceremonias en honor a santa Paula perdurarán en el tiempo, llegando al siglo XIX y apareciendo en las Actas Capitulares catedralicias un mandato en el que se insta a realizar vigilia y misa cantada en el día de los Fieles Difuntos.

Igualmente encontramos aniversarios de misas perpetuas y, de nuevo, en honor a una advocación de María. En esta ocasión, como advocación de los Dolores:

para visperas maitines de dia. Procesión y misa con música y viese misas resadas del señor reverendo para el dia de Dolores las doto el Santísimo Dean Pedro Suares de Valdes con 8504 maravedíes de renta perpetua; y el cabildo en 8 de marzo de 1672 la admitio ad vitam con la de 3000 maravedíes que acrecio a los maitines el señor Albarado y otros 3000 el señor Ibaso ${ }^{22}$.

Los aniversarios de las santas o vírgenes eran el acontecimiento perfecto para manifestar la veneración a las mismas, así como su dotación. En el caso de Málaga, desde 1510 se pueden hallar huellas documentales de celebración a favor de la Purísima Concepción. Las devociones tenían un carácter público o privado, pues las dotaciones apuntan una incipiente inclinación religiosa en los testamentos y documentos notariales ${ }^{23}$. De esta manera se localizaron varios casos en el ACM, entre los que recogemos el siguiente:

Bendito dado por el licenciado don Antonio Clabero, pretendiendo tomar a zenso una casa huerta y jardín situada en el callejón de don Iñigo, pertenesiente a este cabildo por la dotación del aniverssario de la Purisima Consepcion, en la cantidad de dos mil y quinientos ducados dejando los radicados en ella, y sobre otras casas en la calle Nueva y otras dos en los callejones del Perchel con las condiciones de seguridad que constatarían de la escritura que de ello se hubiere de otorga: esta instancia la cometió este ilustre cabildo por decreto de veinte y uno de cuarto de 1671 al caballero doctoral para que practicase las diligencias jurídicas competentes a fin de proporcionar el contrato que se pretendía ${ }^{24}$.

21. Ibidem, 186.

22. ACM, Leg. 2, fol. 83. Aniversarios de obligado cumplimiento en la Catedral de Málaga.

23. F. Fernández Basurte (1994), 196-197.

24. ACM, leg. 20, censos, n. ${ }^{\circ}$ 14, s. f. Petición del licenciado Clavero de tomar a censo de unas propiedades para la dotación para aniversario de la Purísima Concepción. Málaga, 21 de marzo de 1671. 
El culto a María instituía una fuerte identidad en el que los vecinos malagueños tenían la oportunidad de participar pública o privadamente, además de crear pertenencia a una comunidad urbana ${ }^{25}$. María se presentaba como una figura emblemática unida religiosamente a la ciudad malacitana.

Por otra parte, no se debería olvidar que en este periodo la Catedral de Málaga estaba aún en construcción. Las dotaciones y los censos destinados a sufragar los gastos de misas y fiestas aportan una información muy rica a la hora de crear una idea sobre la conformación urbana de la Málaga tras la toma de la ciudad por los Reyes Católicos, además de señalar cómo el cabildo catedralicio aumentaba su patrimonio con las donaciones de los fieles, con los que certificaba el compromiso del cumplimiento de sus funciones con la cesión de una propiedad. Al igual de lo apreciado en otras urbes, tales como Sevilla, esta situación fue importante y abundante en una etapa en la que la consolidación del patrimonio inmobiliario y rústico estaba en pleno crecimiento ${ }^{26}$. Una herramienta muy útil que ayuda a comprender cómo se conformaba la catedral en sus inicios.

En el caso malagueño se ve reflejado, entre los muchos que existen, en el expuesto a continuación:

En las visperas de la Annunçiacion del siguiente dia, missa de dicha fiesta con responsorios por el racionero Bernardo de Montalbo, que lo doto con veinte y ocho mil maravedies de prinçipal y por el racionero Antonio de Esudero, que lo doto con veinte mil maravedies de principal; y por el racionero Albaro de Alcaraz, que lo doto en una casa que dio, que de renta mil çiento y veinte y dos maravedies cada anno, y ocho gallinas ${ }^{27}$.

Otro ejemplo sería el de Cristóbal de Ávila, capellán de la Iglesia Catedral de Málaga, quien "dexo dos memorias, la una de difuntos con missa y vigilia a XIII de abril, y la otra en el octauario de Nuestra Señora de la Conception. Docto para e cada anniversario seis ducados. Dexolos este e sus casas" 28 .

En relación a los capellanes hay que destacar su labor como mediadores y encargados de la realización de misas de difuntos. En la ciudad mala-

25. K. SCHREINER (1996), 379.

26. P. Ostos Salcedo (2011), 304, 308.

27. ACM, leg. 2, n. ${ }^{\circ}$ 1-4, fol. 4. Libro de aniversarios y dotaciones, 1672-1681.

28. ACM, leg. 161, n. $^{\circ}$ 6, fol. 6. Relación de las memorias e aniversarios y procesiones de la Catedral de Málaga hacia 1580. 
citana los estatutos de la Catedral recogen la existencia de 12 capellanías del coro $^{29}$. A nivel peninsular, otros autores han demostrado la importante cantidad de capellanías en ciudades donde este fenómeno concreto comienza a extenderse en los territorios tomados a los musulmanes, en particular en la capital hispalense durante el siglo XIII. Estas constituyeron una función fundamental tanto a nivel religioso como económico ${ }^{30}$. Su principal propósito era garantizar las disposiciones de los difuntos y llevar a término el acuerdo pactado entre particular e institución ${ }^{31}$.

Gracias a estas fundaciones se dispuso de capillas para poder oficiar las misas destinadas a facilitar la salvación de las almas. En la Edad Moderna podemos observar un incremento considerable de las misas perpetuas y de capellanías, y en las fundaciones de aniversario. Estas peticiones se extenderán al común del pueblo, pero como se ha visto en los distintos casos mencionados el número de misas dependerán del despliegue económico de cada persona ${ }^{32}$. El apogeo de las memorias podría fijarse en torno al siglo XVII, y su decadencia a fines del mismo siglo e inicios del siguiente, cuando las fundaciones fueron prohibidas en el año $1763^{33}$.

Si atendemos a las mandas de última voluntad analizadas para la capital malacitana, el $89 \%$ de los testamentos del siglo XVIII solicitaban misas pro animas. Como se ha indicado anteriormente, dependiendo de la capacidad económica del testador o testadora, el número de misas solicitado sería superior o inferior. Estadísticamente podemos distinguir cinco grupos. Dentro del primero de ellos tendríamos a los otorgantes que encargaban en torno a 50 misas, los cuales representaban un 7,1\% del total por este concepto considerado; en el segundo grupo oscilan entre 100 y 150 misas demandadas, donde el porcentaje de testadores acapara el 30,5\%; en el tercero vendría delimitado entre 150 y 400 misas, que conllevaría al 34,2 \% de los testadores; el cuarto grupo alcanza de 450 a 1000 misas, con un 14,5; el último, respondería al a los testadores que conferían más de 1350 misas y fundaban una misas de aniversario o perpetua, respondiendo al 9,7 \% de los testadores ${ }^{34}$.

29. L. Morales García-Goyena (1907), 35.

30. F. Martínez Gil (1991), 972.

31. P. Ostos Salcedo (2011), 303.

32. M. Reder Gadow (1986), 128-129.

33. F. Martínez Gil (1991), 973.

34. M. Reder Gadow (1986), 130. 


\subsection{Fiestas}

Otro de los puntos que se ha podido abordar es el proceso de las fiestas marianas. En ellas resalta la importancia otorgada a la actividad musical en las capillas. En el siglo XVI el concepto de fiesta envuelve la celebración de tiempos litúrgicos, procesiones, asistencia a rituales religiosos y preponderancia de la alabanza por encima de los quehaceres propios del día a día. La fiesta vendría a significar la conmemoración del ritual religioso, incluyendo las vísperas, como en el caso de la Inmaculada Concepción ${ }^{35}$.

Aunque la veneración de la Purísima tiene como raíz la llegada de los Reyes Católicos a la ciudad malacitana, no fue hasta entrado el siglo XVII cuando se comienza a desarrollar con exaltación. El 8 de diciembre de 1654 los cabildos malagueños, municipal y eclesiástico, juran la defensa del misterio inmaculadista ${ }^{36}$. Dos siglos después, tras la declaración del dogma el 8 de diciembre 1854, la fiesta de la Inmaculada se pone en marcha en Málaga, pero el azote de una epidemia de cólera retrasó el acontecimiento hasta los días 2 y 3 de junio del siguiente año ${ }^{37}$.

Las fuentes documentales muestran las cuentas y los preparativos seguidos para realizar el itinerario durante el ceremonial: himno, gastos para pliegos de papel, desembolsos para pagar a músicos y maestros de capilla, adornos para la procesión, iluminación del lugar de celebración con velas y lámparas de araña, gastos de limpieza e incluso fuegos artificiales. Estos acontecimientos recogidos en los documentos plasman y reconstruyen la ceremonia de la Purísima en la localidad.

La fiesta y fundación de esta festividad queda descrita minuciosamente en los legajos del Archivo Catedralicio. Ajustados al pertinente protocolo, las autoridades acometen los preparativos donde incluyen misas, limosnas, compra de materiales para la decoración del templo y la urbe, y un largo etcétera. En el siglo XVIII se funda la capilla dedicada a la Purísima Concepción. Las misas que se le destinadan aparecen recogidas nítidamente en los fondos consultados:

Y el señor don Leonardo Urtusaustegui, dignidad del Arcediano de Velez, que es el devoto y fundador de dicha dotación, explico que esta consistia en fundar en la Capilla de Nuestra Señora de la Concepcion, a honrra y gloria

35. S. Rodríguez Becerra (2000), 156.

36. F. Fernández Basurte (1994), 198.

37. A. Camino Romero (2005), 649. 
suia consta en esta santa Ygleisa Catolica en sus siete principales Misterios. Señala 100 misas resadas con limonas de cinco reales cada una, que ha de aplicar por el fundador y decirlas en el altar de la citada capilla en todo su novenario en las fiestas señaladas y en todos los demas dias del año en que se celebre festividad de la Virgen, lo que ha de hacer por si opta otro sacerdote a quien lo encargue quando por enfermedad o ausencia no pudiese.

Se regulan para esta dotacion 21 libras de cena a diez maravedís.

-Por los ocho motetes y letanias que ha de cantar la capilla de musica a 20 reales cada dia

-160 reales por las 100 misas que ha de decir el sacristan

-500 reales que las tres partidas componen

-900 reales por lo que resultan sobrantes ${ }^{38}$.

La música vuelve a tener protagonismo en esta conmemoración, al quedar descrita la fundación en su honor. Por desgracia, no ha quedado constancia de la armonía musical, pero sí de la letra del himno. Lo recogido en el programa correspondiente a los actos celebrados en las fechas indicadas más arriba, son un magnífico testimonio del procedimiento seguido y del texto referido al himno dedicado a la Virgen.

38. ACM, leg. 553, n. ${ }^{\circ}$ 16, fol. 2-4. Documentos para la celebración de la fiesta de la declaración del dogma de la Purísima Concepción, 1855. 


\section{PROGRAMA}

de las funciones que el Obispo y Cabildo de la Santa Iglesia Catedral de Málaga, han acordado celebrar en ella, á sus espensas, el 2 y 3 de Junio de 1855, en accion de gracias al Todopoderoso, con el plausible motivo de la declaracion dogmática del Misterio de la Inmaculada Concepcion de Maria Santísima, verificada el dia 8 de Diciembre de 1854.

\section{DIA 2 DE JUNIO.}

\section{$\mathbf{E}$}

n este dia, vispera de la solemnidad, à las doce, se anunciarâ la fiesta con tres grandes repiques en esta Santa Iglesia, y en la veleta de su torre y balcon inmediato se hallaran colocados un gallardete $\mathbf{y}$ cualro banderas españolas.

Por la tarde, concluidas las Visperas y Mavtines del dia, se celebrará una procesion solemne con la sagrada imágen de la Santisima Virgen, colocada de antermano en andas en la capilla de la Goncepcion. Reunidos en ella el Obispo, Cabildo, Ministros y Colegio Seminario, se cantara á toda orquesta un Himno, compuesto expresamente por el Maestro de Capilla. En seguida se cantará el Ave maris Slella, y se ordenará la procesion por la misma estacion que la de la oclava del Corpus, con hachas encendidas, y la Santisima Virgen será conducida en hombros de los Capitulares, llevandose además el estandarte de este Misterio. Concurrirá la correspondiente escolta y banda dé Música de la Milicia Nacional, para cuya asistencia se invilará por la Comision al Sr. Álcalde; durante la procesion no cesarán los repiques.

Concluida esta, colocada la Santisima Virgen en un altar portatil, suntuosamente adornado en el Presbiterio de la Capilla mayor, al lado def Evangelio, y encendida la iluminacion interior del Templo, se cantarán unas solemnes Visperas de la Virgen, a toda orquesta, con lo que terminarả este acto.

Por la noche, de nueve á doce, habrá una vistosa iluminacion en la torre y fachada, y grandes repiques, que alternarán con las tocatas de una banda de Música Militar cólocada en sú balcon principal.

\section{DIA 3 DE JUNIO.}

Al alba de este dia habna tres grandes repiques, que se repetirán mas tarde concluida la Misa conventual y Horas canónicas.

$\Lambda$ las once en punto, estando el interior del Templo perfectamente iluminado, se celebrará por el Dean ó Dignidad mas antiguo la Mfisa de la solemnidad, que sera oficiada por una lucida y brillante orquesta. Predicará el Licenciado D. Juan Nepomuceno Lopez, Canónigo Magistral; y concluida la Misa se cantara por la misma orquesta un solemne $T e$ Deum... que entonará el Obispo revestido de Medio-Pontifical.

Para la funcion de este dia se convidarán a todas las Autoridades asi Civiles eomo Militares, Diputacion Provincial y Excmo. Ayuntamiento, personalmente por la Comision del Cabildo, y por medio de esquelas á las demás Corporaciones y personas distinguidas de esta capital, Oficialidad do la guarnicion y de la Milicia Nacional.

Al principiarse la Misa se expondra el Santisimo Sacramento, que continuará manifiesto todo el dia, con la correspondiente vela de Capitulares.

Por la tarde, concluidas las Visperas del dia, habra un intermedio hasla las seis, en que encendida ya la iluminacion interior, se entrará en Maytines, que se dirán semicantados como eu uno de los dias de la octava del Corpus. Despues se cantará a toda orquesta el llimno ya referido. una Salve y las Letanias de la Sanlisima Virgen, y ûltimamente el Motete para ocultar i y concluido, S. B. L. bendecirá al pueblo con el Santisimo Sacramento.

Por la noche a las nueve se repiten los repiques, la iluminacion esterior de torre y fachada. y las tocatas de la banda de Musica tilitiar, todo como en la noche de la vispera, con lo cual terminarin estas solemner funciones.

Imagen 2. Programa acordado por el obispo y el cabildo para la celebración de la declaración dogmática del Misterio de la Inmaculada Concepción de María Santísima.

ACM, leg. 301, n. ${ }^{\circ} 1$.

(C) Baetica. Estudios Historia Moderna y Contemporánea, 38, 2018, 115-133. Facultad de Filosofía y Letras, Universidad de Málaga. Departamento de Historia Moderna y Contemporánea 


\title{
FIIMINO \\ A LA SANTISIMA VIRGEN MARIA,
}

\author{
QWE DRER GAFTARST
}

\begin{abstract}
Inmaculada de la Madre de Dios.

\section{CORD.}

¡GLonts, Grontal LA Amosis

Deit. Hosumsa jomioso,

Vureo escoumaka victosioso

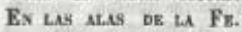

Toda hermosa eres, Manis,

Mancha alguana en $t i$ no fue.
\end{abstract}

en las funciones solemnes que el Oblspo y Cabilio de la Santa Iglesia

Catedral de Málaga celebran el 2 y 3 de Junio de 1855 , con motivo de la declaracion dogmatiea del Misterio de la Coneepelon

Gloria canta el firmamento

En las arpas celestiales,

Y responden los mortales

Con los himnos del amor.

Inefable es el contente

Para el gozo del Señor.

Toda hermasa eres, Manis.

Mancha alguna en $t i$ no fue.

¡Glonts, Groma! \&c.

Toda pura, loda bella

Eres, Madre, al' Humanado;

Tu eandor inmaculado,

$Y$ sin nube tu beldad.

Dice alegre toda estrella,

Tanta gloria celcbrad.

Toda hermosa eres, Mania,

Mancha alguna on tis no fue.

¡Gronia, Grontal Se.

Toda bella, toda pura

Eres, Hija del Bterno.

Que a la sierpe del Averno

Ia cerviz hollaste asi.

No hay de Dios exoelsa hechura,

Bella y fuerie a par de if.

Toda hermasa eres, Manis,

Mancha alguna at $t$ no fue.

Gooms, Grons, Sin.
Toda bella, dalce Esposa

Del Espiritu divino,

Eres astro matutino

Que las sombras ahuyento;

$Y$ tu luz maravillosa

nunca, nunca desmayo.

Toda hermosa eres, Muria,

Mancha alyuna en ti no fue.

¡Gloms, Gronu! \&c.

De este ornato ya blasona

EI que anhelo fue incesante,

BI que fue ruego triunfante,

Rl que siempre honor te fue:

Mas con el ya te corona

La palabra de ia $\mathrm{Fe}$.

Toda Aermosa eres, Mania,

Mancha alguna en $u$ no fue.

jGoma, Gronis! de.

\section{corto.}

tGuoms, Gromen! La ancosis

Dei. Hosuxxa rovinos,

Verno excosala victousoso

Ex Lis ales or $4 \mathrm{PE}$.

Toda Kerwasa eres, Msais,

Mancha alguna en if no fue.

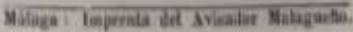

Imagen 3. Letra del Himno a la Santísima Virgen María, con motivo de la declaración dogmática del Misterio de la Concepción Inmaculada de la Madre de Dios.

ACM, leg. 301, n. ${ }^{\circ} 1$. 
Esta celebración perduró en el tiempo y actualmente continúa siendo motivo de celebración. En concreto, en diciembre de 2004, se conmemoró su 150 aniversario y el itinerario seguido fue muy similar al primigenio. La diócesis organizó un ciclo de conferencias previo al acto, para comenzar después con el triduo dispuesto destinado a su festejo en el que se incluían misas, procesiones desde la parroquia de los Santos Mártires a la Catedral, vísperas solemnes y la intervención de la coral Santa María de la Victoria ${ }^{39}$.

Los fondos documentales han recogido las descripciones de las fiestas. Se ha destacado la de la Purísima al ser una de las más relevantes en la capital malagueña y tener una rica fuente de información. Las fiestas religiosas constituyen un medio para acercarnos a la realidad social y simbólica de los tiempos pretéritos. La religión y la fiesta se erigen como factores vitales para la configuración cultural de las sociedades ${ }^{40}$.

\section{CONCLUSIONES}

Los datos recogidos a través del análisis de las fuentes documentales han expuesto una relevante y fructuosa información acerca de la mentalidad religiosa malagueña. Se han analizado los libros donde el ceremonial quedaba recogido. Las finalidades principales de este análisis han sido la aproximación a las distintas advocaciones de la Virgen María de la Catedral de Málaga a través de las misas y fiestas, así como los recursos empleados en ella. A través de los datos obtenidos, hemos comprobado las relaciones entre las disposiciones contenidas en los libros y documentos, y los solicitantes de las mismas, llegando a vislumbrar el perfil de cada peticionario y su estatus socioeconómico.

Los libros de misas y las peticiones recogidas en ellas aportan una información muy interesante para analizar las mentalidades y preocupaciones de las comunidades religiosas ante la muerte ${ }^{41}$. Se han mostrado las particularidades religiosas de los difuntos y puesto de manifiesto la dicotomía entre grupos sociales.

Las rentas y las cartas de censo aseguraban los pagos de los gastos producidos por la demanda de las ceremonias religiosas. Los libros reflejan los compromisos adoptados por la catedral para rezar por sus feligreses.

39 S. E. Rodríguez de Tembleque García (2005), 106-107.

40 S. Rodríguez Becerra (2000), 156-157.

41 P. Ostos Salcedo (2011), 312. 
Estos datos permiten añadir información a la historia de la catedral malagueña, desde enfoques diferentes.

En cuanto a las fiestas, el espacio urbano refleja el carácter religioso de la ciudad. La celebración de fiestas con carácter sacro trasluce el pensamiento religioso que se promocionaba desde los poderes civiles y religiosos ${ }^{42}$. Por ello, la reconstrucción de ceremonias concretas a partir de documentos ayuda a entender este tipo de religiosidad que concernía a los celebrantes de la Purísima.

La aproximación llevada a cabo en este trabajo podría ser un escenario muy estimulante para completar y ampliar en el futuro las investigaciones hasta ahora acontecidas. La preocupación ante la muerte y la mediación de María en ella destaca en una sociedad malagueña en la que prevaleció su culto. Un culto continuado hasta llegar al tiempo presente.

\section{BIBLIOGRAFÍA}

Camino Romero, Andrés (2005), “La devoción a la Inmaculada Concepción en Málaga a través de varias asociaciones religiosas”, en F. J. CAMPOS y FernándeZ DE Sevilla (coord.), La Inmaculada Concepción en España: religiosidad, historia y arte: actas del simposium, 1, Ediciones Escurialenses, Real Centro Universitario Escorial-María Cristina, El Escorial, pp. 645-668.

Collado Ruiz, María José (2012), "Las peticiones de ciclos de misas en los testamentos granadinos en los siglos XVI-XVII”, Revista de Humanidades y Ciencias Sociales, 2, pp. 303-318.

Fernández Basurte, Federico (1994), “El concejo y las fiestas de la Inmaculada en Málaga. 1640”, Espacio, Tiempo y Forma, Serie IV, H. ${ }^{a}$ Moderna, 7, pp. 195-210.

Gómez Navarro, Soledad (2008), “Un momento ideal para acordarse de los Santos: Cuando la muerte llega. La cláusula testamentaria de la intercesión en la España Moderna”, en F. J. Campos Fernández de Sevilla (dir.), El culto a los Santos. Cofradías, devoción, fiestas y arte, Ediciones Escurialenses, Real Centro Universitario Escorial-María Cristina, El Escorial, pp. 57-74. GonzÁlez SÁnchez, Vidal (1994), Málaga. Perfiles para su historia en documentos del Archivo Catedral (1487-1516), Málaga.

Le Goff, Jacques (1985), El nacimiento del Purgatorio, Taurus, Madrid.

Martínez Gil, Fernando (1991), Muerte y sociedad en la España de los Austrias, t. II, Universidad Complutense, Madrid.

Martínez Solaesa, Adalberto (1996), Catedral de Málaga: órganos y música en su entorno, Universidad, Málaga.

42 F. Fernández Basurte (1994), 209. 
Martínez Solaesa, Adalberto y Naranjo Lorenzo, Luis (2004), Música y cultura: perspectiva histórica, Aljibe, Málaga.

Morales García-Goyena, Luis (1907), Estatutos de la Catedral de Málaga, Universidad, Granada.

Ostos SAlcedo, Pilar (2011), “Documentos para el 'ánima salvar y los herederos apaciguar' en la Sevilla medieval. Testamentos y dotaciones de capellanías”, Archiv für Diplomatik Schriftgeschichte, Siegel- und Wappenkunde, 57, pp. 275-314.

Pino Romero, Antonio Tomás (2012), “Música en honor de los Santos Patronos de Málaga Ciriaco y Paula”, Boletín de Arte, 32-33, pp. 177-206.

Reder Gadow, Marion (1986), Morir en Málaga. Testamentos malagueños del siglo XVIII, Universidad, Málaga.

Righetti, Mario (1955), Historia de la liturgia I, La editorial católica, Madrid.

Rodríguez BECERra, Salvador (2000), "Religión y fiestas en Andalucía. Reflexiones metodológicas”, en D. GonzÁlez Cruz (coord.), Religiosidad y costumbres populares en Iberoamérica: [actas del Primer Encuentro Internacional celebrado en Almonte-El Rocio (España) del 19 al 21 de febrero de 1999, Universidad, Huelva, pp. 153-168.

Rodríguez de Tembleque García, Susana Elena (2005), “Actos en honor de Nuestra Señora de la Concepción”, La Saeta, 35, pp. 101-107.

Schreiner, Klaus (1996), María. Virgen, Madre, Reina, Herder, Barcelona.

Torre Molina, María José de la (2010), “La Catedral de Málaga como modelo de estudio de la música en el ámbito catedralicio español e hispanoamericano: logros, perspectivas y retos”, en A. García ABÁsolo (coord.), La música de las catedrales andaluzas y su proyección en América, Universidad, Córdoba, pp. 299-341. 